AperTO - Archivio Istituzionale Open Access dell'Università di Torino

\title{
Metaphysics and Ontology
}

\section{This is a pre print version of the following article:}

Original Citation:

\section{Availability:}

This version is available http://hdl.handle.net/2318/143061

since 2021-02-21T11:52:39Z

Publisher:

Brill

Published version:

DOI:10.1163/9789004269347_003

Terms of use:

Open Access

Anyone can freely access the full text of works made available as "Open Access". Works made available under a Creative Commons license can be used according to the terms and conditions of said license. Use of all other works requires consent of the right holder (author or publisher) if not exempted from copyright protection by the applicable law. 


\section{Bridging the Analytical Continental Divide}

A Companion to Contemporary Western Philosophy

Edited by

Tiziana Andina

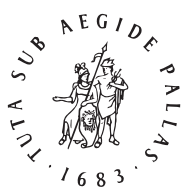

B R I L L

LEIDEN | BOSTON 
Original publication: T. Andina (a cura di), Filosofia contemporanea. Uno sguardo globale, Carocci, Roma, 2013.

This publication has been typeset in the multilingual 'Brill' typeface. With over 5,100 characters covering Latin, IPA, Greek, and Cyrillic, this typeface is especially suitable for use in the humanities. For more information, please see brill.com/brill-typeface.

ISBN 9789004254961 (hardback)

ISBN 9789004269347 (e-book)

Copyright 2014 by Koninklijke Brill Nv, Leiden, The Netherlands.

Koninklijke Brill Nv incorporates the imprints Brill, Brill Nijhoff, Global Oriental, and Hotei Publishing. All rights reserved. No part of this publication may be reproduced, translated, stored in a retrieval system, or transmitted in any form or by any means, electronic, mechanical, photocopying, recording or otherwise, without prior written permission from the publisher.

Authorization to photocopy items for internal or personal use is granted by Koninklijke Brill Nv provided that the appropriate fees are paid directly to The Copyright Clearance Center, 222 Rosewood Drive,

Suite 910, Danvers, MA 01923, USA. Fees are subject to change.

Brill has made all reasonable efforts to trace all rights holders to any copyrighted material used in this work. In cases where these efforts have not been successful the publisher welcomes communications from copyright holders, so that the appropriate acknowledgements can be made in future editions, and to settle other permission matters.

This book is printed on acid-free paper. 


\section{Contents}

Preface ix

List of Contributors $\quad$ xi

Introduction 1

Maurizio Ferraris

1 The Death and Resurrection of Philosophy 1

2 Philosophy in Postmodern Times 1

3 The Old Synthesis-Relativism 4

4 The Analytics Land on the Continent 5

5 The New Synthesis: Realism 6

1 Metaphisycs and Ontology 8

Tiziana Andina and Andrea Borghini

1.1 The Beginnings 8

1.2 Things that Exist 23

1.3 Regional Ontologies 29

2 Epistemology 38

Maria Cristina Amoretti and Annalisa Coliva

2.1 The Traditional Definition of Knowledge 38

2.2 Justification and Knowledge 45

2.3 Scepticism and the External World 52

2.4 Epistemic Relativism 58

3 Language 67

Carola Barbero and Stefano Caputo

3.1 The Dominant Paradigm 67

3.2 Beyond the Dominant Paradigm 76

4 Logic and Mathematics 108

Andrea Pedeferri and Francesco Berto

4.1 Philosophy of Logic and Logical Philosophy 108

4.2 Theories of Truth $\quad 115$

4.3 Model Theory 121

4.4 Modal Logic and Possible Worlds 127

4.5 Conditionals 137

5 Mind 145

Luca Angelone and Daniela Tagliafico

5.1 The Problem of Consciousness 147

5.2 The Extended Mind 163

5.3 The Sensorimotor Paradigm 171 
6 Science 177

Elena Casetta and Giuliano Torrengo

6.1 Philosophy of General Science 177

6.2 The Philosophy of Special Sciences 194

7 Ethics 206

Francesca De Vecchi, Sergio Filippo Magni and Vera Tripodi

7.1 The Discussion on the Foundations of Ethics 206

7.2 Acting in the Social World 218

7.3 Sex and Gender, the Individual Beyond the Limits of Classification $\quad 230$

8 Politics 241

Valeria Ottonelli and Italo Testa

8.1 Power and Democratic Legitimacy 242

8.2 Recognition and Oppression 248

8.3 Body Politics 254

8.4 Distributive Justice 259

8.5 Human Rights, Global Justice, Immigration 263

9 Aesthetics 270

Alessandro Arbo and Chiara Cappelletto

9.1 Art, Perception, Beauty 270

9.2 Neuroaesthetics 275

9.3 Difficulties of Aesthetic Judgment 284

9.4 Image and Reality: An Ancient Competition 290

9.5 Work/Works 294

Bibliography 299

Index 343 


\title{
Metaphysics and Ontology ${ }^{1}$
}

\author{
Tiziana Andina and Andrea Borghini
}

\subsection{The Beginnings}

Metaphysics and ontology, at a glance, circle around a simple question: what exists? If it is true, as there are many ways of verifying, that human behavior is characterized by a pronounced level of conceptualization, metaphysics and ontology study a central aspect of living, not only from a theoretical perspective, but also from a practical one. Every gesture, even the most quotidian, whether we realize it or not, is based on a certain way of perceiving the world that surrounds us. That is why delving into this aspect becomes one of philosophy's primary tasks, even if it is often accompanied by a significant level of theoretical difficulty.

What is the relationship between ontology and metaphysics? First of all, to clarify, the two terms have very different origins which date back to the 1600 s and the first century B.c., respectively. These are two sides of the same coin which, as we will see, have been depicted in various different ways throughout the centuries (infra, 1.2). In this chapter we have decided to adopt a distinction that has been supported by various contemporary authors, among whom is Achille Varzi, ${ }^{2}$ for example, and which can be traced back to Edmund Husserl and even Scholasticism. In short, the assumption is that when one is dealing with the study of key principles with which to discuss what exists, it is better to keep separate those whose formulation abstracts from the specific realm of the discourse (art instead of math or biology), and those who, instead, find justification within a specific area. Let us call the first principles metaphysical, and the second principles ontological. Our treatment will follow this distinction. ${ }^{3}$

1 The chapter was conceptualized collectively; however Andrea Borghini wrote sections 1.1., 1.1.2., 1.1.4., 1.1.5., 1.1.6., 1.1.7., 1.1.8., and Tiziana Andina wrote sections 1.2., 1.2.1., 1.3., 1.3.1., 1.3.2., 1.3.3., 1.3.4., 1.3.5. This chapter has been translated into English by Julia Heim.

2 Cf. Varzi 2005, especially the first chapter. For a more detailed overview of the topics discussed here, see also Loux 2002.

3 It is worth remembering, in this regard, that a theoretical distinction of a different kind is offered by Maurizio Ferraris (2001) who proposes adopting a distinction which separates the 


\subsubsection{At the Roots of Metaphysics}

For "metaphysics" what is meant is a series of treatises written by Aristotle and later gathered under that title. Their first edition was compiled by Andronicus of Rhodes in the first century B.C. after an incredible finding about two hundred and fifty years after the death of the famous philosopher. Not knowing how to label the text that came after "Physics," Andronico used the term "Metaphysics," which literally means "after physics." Since the text had to do with reality in its most fundamental and general aspects, later critics thought that "metaphysics" had to do with what was beyond the realm of investigation within physics. In fact, as we shall see, metaphysics - when taken as a discipline of philosophy - has to do with questions that lie beyond the possibilities of empirical inquiry, since it investigates the conceptual structures that characterize the inquiry itself, including the relationship between object and subject.

Though the term was introduced close to the Christian age, this does not mean that metaphysics was not previously expatiated. On the contrary, many of the most expansive works in the realm of metaphysics come from the period that preceded the neologism. A list of them might include the treatises of Parmenides, Anaxagoras, Pythagoras, Euclides, Zeno of Elis, Plato's Parmenides and many other classics from the Ancient Western Tradition. Likewise, important authors and works of other philosophical traditions also dealt with the subject, such as the Tao Te Ching (a classic Chinese text dating back to at least the third century B.c.), and the work of the two Indian Buddhist monks Nāgārjuna (approximately 150-250 A.D.) and Vasubandhu (fourth century A.D.). We might also add numerous other literary and religious texts that contain reflections on the structure of reality.

During the Middle Ages there was a creative flourishing of metaphysical positions. To formulate an apt theology you must know how to precisely state the make-up of God, the trinity, angels and the soul with relation to the body, and so on. Debates that stem from the famous dispute between the nominalists and realists (we will discuss this later on) during the most intense period of scholastic medieval times - between the eleventh and fourteenth centuriesare still with us today, like the dispute over the nature of relations or accidental and essential properties. Metaphysical inquiry is also central to philosophical

realm of what is (ontology) from the realm used to investigate what we know based on what is (epistemology). The confusion between these two realms would cause a relativism, which often leads to markedly unrealistic positions, as with a large portion of the philosophy of the 1900 s when it was believed that reality was essentially the fruit of social construction. From the application of certain conceptual plans there was no longer a way to separate a reality independent of the subject from the subject that knew this reality. 
reflections of the modern age, characterized by radical positions that, even today, mark the large majority of our conceptual limits of the world-from the dualist metaphysics proposed by René Descartes to Spinozian monism, and from the monadology of Gottfried Leibniz to the empiricism of John Locke and David Hume, to the Kantian distinction between phenomena and noumena.

It might be precisely with Kant that a certain type of analysis of reality ends. While pre-Kantian philosophy began with the object- therefore with metaphysics - to develop an ethics, an epistemology, a theology, etc., in much of the post-Kantian philosophy the intentional acts of the subject take precedence over the analysis of the perceived object. ${ }^{4}$ The perceived object exists only in as much as it is possibly contained by thought and the properties of this thought are what must be examined. Metaphysics returns to center-stage almost simultaneously with what are today the two principle Western traditions: continental and analytical philosophy. In terms of continental philosophy, it suffices to remember that both the ideas of Martin Heidegger and those of Jean-Paul Sartre are difficult to understand without an analysis of their metaphysical positions, and analogous considerations are necessary in the case of authors like Maurice Merleau-Ponty and Emmanuel Lévinas. On the other hand, Bertrand Russell and George E. Moore-influenced also by philosophers from the old continent like Bernard Bolzano, Franz Brentano, Alexius Meinong and Gottlob Frege - two analytic philosophers, bring genuine metaphysical questions to the forefront. In the second half of the 1900s analytic philosophy was in the midst of a true flourishing, especially during the last thirty years of the century, thanks to the work of authors like Peter Strawson, David Wiggins, Willard V. O. Quine, Roderick Chisholm, David Lewis, Alvin Plantinga, Peter van Inwagen, Jonathan Lowe, Ted Sider and, to mention a few Italian authors, Maurizio Ferraris, Enrico Berti, Roberto Casati and Achille Varzi. ${ }^{5}$

This same history of metaphysics gives us something to discuss and even the few reflections we have given up to this point are disputed among the experts. The themes and approaches are many and varied. As such, the discussion must be organized based on a selection. ${ }^{6}$ Therefore, six fundamental ideas have been

4 Cf. Ferraris 2001, 2013, for a more in depth analysis.

5 Varzi 2008 gathers an ample selection of key contemporary metaphysical texts in their Italian translations; in it are specific references to a large number of the questions raised here. Useful readers in English are Sider, Hawthorne and Zimmerman (2008) as well as Loux (2001).

6 Cf. Mou \& Tieszen 2013 for a useful study including the contemporary scholarship that explores how relevant resources from different philosophical traditions make joint contributions to the development of contemporary philosophy. 
chosen and will be examined using a theoretical approach and following the analytic tradition. Before continuing with their analysis, however, it is helpful to frame the discussion by analyzing two related arguments: the relationship between common sense, science and metaphysics on one hand, and the intellectual duty of philosophers who deal with metaphysics on the other. Let us look at them in that order.

\subsubsection{Common Sense, Science and Metaphysics}

How many grams of carbohydrates, proteins and lipids did you consume during your last meal? We are certain that many, these days, would know how to answer a question of that kind with sufficient proximity. And yet, no one has ever seen a carbohydrate, a protein or a lipid. We are dealing with theoretical terms, without direct observable correlations, that have meaning inside a theory of food chemistry. Analogous considerations could be made for electrons, protons, neutrons and so on. With a book in our hands we believe that we are dealing with $a$ solid, rectangular, unique object whose parts are spatially connected; and yet based on the description that a physicist could give, we are talking about a multitude of particles that move at lightning speeds. A scientific image of the world does not depend on the senses; in fact, it often contradicts them, trusting instead other revelatory instruments. On the contrary, an "every day" picture of the world, what we will call the "common sense picture," depends on our sensorial analyses. The ocean is salty, ice cream is sweet, ricotta is heavy and a turtle is slow-all of these adjectives are used in reference to the human perceptive system. Obviously, both scientific practices and daily living suggest more than just one structure of reality. As for science, we have varying theoretical alternatives with respect to the origins of the universe, what the fundamental particles of physics are, what the fundamental bonds in organic chemistry are, or how to understand evolution by natural selection. Analogously, some people live out their daily lives with the belief that the world is populated by gods or even ghosts, that miracles are possible, that cows have a soul, that dogs are food, and others refuse some or all of these things. In sum, science and common sense seem to articulate answers based on the structure of reality. However, considering that metaphysics deals with precisely this, how should it position itself in the face of the other two modes of thought? Is there a hierarchy of interests? Do privileged levels of analysis exist?

The questions raised are particularly relevant to metaphysics because they problematize the concept of existence. Let us return to the situation with the book. One of the ways to see the matter is the following. We have a spatiotemporal location in which we say there is a book; at the same time, we might 
say that in that location there are multiple moving particles; and the list of alternate possibilities could go on. To cite a few, one possibility would be based on the chemical composition of the area, another on the organic material, and another still on the semantic contents of the book. These accounts tell us that in that location there are things, but each arrives at a different result with regard to what those things are. And so a meta-account which synthesizes them all, at least for now, is yet to come.

What was said of the book is also true for everything we have eaten today, for the ocean, the beach and the sun, for Botticelli's Venus and for every living being including humans. What relationship remains between what a meticulous particle-physicist, an organic chemist, an anatomist and my sister could explain about the spatio-temporal area I am occupying at this moment? More generally, what relationship remains between the different accounts of the same pieces of reality? Metaphysical reflection finds one of its principle tasks precisely in this field.

We can distinguish this relevant metaphysical position by following two directions. The first has to do with the degree of deference (it might be better to call it "epistemic trust") that we have toward science (cf., infra § 6.1). According to the first position-let's call it "scientific metaphysics" - things only exist that figure into the best scientific theory we have at our disposal (cf., for example, Armstrong 1989; Lewis 1986). On the other hand we might see that a position of this kind risks being myopic for two reasons. First and foremost, aside from some principles, we don't have a substantially agreed upon scientific theory of natural phenomena. ${ }^{7}$ Furthermore, it seems difficult to be able to explain, in scientific terms, the meaning that many Italians give to lentils at New Year or the Festival of Sanremo, Polynesia, or the Postal Service-these are rooted in social acts the significance of which (at least in appearance) are not describable within the terms of a scientific theory. Clearly scientific metaphysics (cf. Lewis 1986) would interject that the examples in question constitute poor descriptions of physical events. However, it seems that one of the main characteristics of human beings is their capacity to organize their lives around objects and events whose significance cannot be elaborated in scientific terms, as such, scientific metaphysics, in this case, could devalue something of importance. Those scientific metaphysicians who fall under this last category should be further divided in two sects, the first being the supporters of a "liberal metaphysics" who allow for a plurality of legitimate metaphysical positions (cf. Dupré 1995); this sect finds difficulty in individuating a notion of truth that is not relative to the adopted position. Then there is "descriptive metaphysics,"

7 Cf., among others, Dupré (1995). 
for which common sense is supposed to get the better of scientific accounts. ${ }^{8}$ Unfortunately, it is extremely difficult to define common sense in an exact way, and so the sect based on it risks exposing itself to indeterminacy.

The second direction of the metaphysical reflection of the relationship between different accounts of reality has to do with philosophical behavior in relation to existence, as separate from references to other scientific theories. Let us again consider our book. "Eliminativism" would hold that there is only one true account for that spatio-temporal area-all of the other accounts are false and therefore must be eliminated. ${ }^{9}$ On the other hand, the majority of eliminativists are also scientific metaphysicists who have opted for an articulation of an account of the spatio-temporal area within elementary-particle terms. In literature, eliminativist and non scientific solutions also exist. "Reductionism," on the other hand, supports the belief that all of the accounts in question (and all others that are believed to be plausible) are true; however, they are true in virtue of the existence of one single object - we are talking about the fundamental particles, or the book. The existence of everything else is metaphysically (even if not conceptually) reduced to the existence of that kind of object. ${ }^{10}$ Many philosophers today support reductionist positions even if they often do it "locally." For example, they might argue that the mind is reduced to the body, or rather that biological facts may be reduced to chemical processes which, in turn, may be reduced to physical processes. Finally, "pluralism" (again cf. Dupré 1995) supports a multiplicity of true accounts. Again, the difficulty in this case lies in finding a way to maintain a strong notion of truth while defending relativism. Numerous pluralist metaphysicians are also conventionalists, or rather, they believe that the truths of an account exist because of convention. The book, therefore, exists because of a daily convention among the speakers of our language, and particles exist because they are postulated through the conventions of scientific theory. If something exists outside of conventions it remains a fundamental problem.

\subsubsection{The Two Metaphysics: Describing and Prescribing}

Both of the directions followed in the preceding section suggest two diverse conceptions of metaphysics: one "absolute" and the other "relative." Eliminativism and reductionism belong to the first type, as do scientific metaphysics and descriptive metaphysics. Pluralism and liberal metaphysics belong, on the other hand, to the second type. As for relativists, metaphysical discussion

\footnotetext{
8 Cf. for example, the section dedicated to naïve knowledge in Ferraris 2008, 273 et seq.

9 Cf. Varzi 2001, 24-25.

$10 \quad$ Again, cf. Varzi 2001, 24-25.
} 
must refer to a type of investigation which traces out the main coordinates. In this sense the question remains open as to whether or not a core of principles exists which every investigation, in part or in total, accepts or whether relativists refrain from this (however minimal) engagement. Some of these questions are at the core of the work of Willard Quine, one of the protagonists of the analytic philosophical debate of the twentieth century. On the other side, the absolutists consider metaphysics to be the realm of investigation that researches valid universal principles. Some of these principles are "formal," or rather valid, independent of the specific material constitution of the world; for example, they belong to a category of mereological principles (that govern the relationship between the parts and the whole) or the relationship of ontological dependence, discussed below. Other principles, on the other hand, are "material," or rather they depend on the specific perspective regarding the last elements. An eliminativist who considers reality to be composed of strings (as supported by the so called "string theory") will sustain different material principles with respect to an eliminativist who follows common sense. Some make the distinction between formal principles and material ones coincide with the distinction between metaphysics (formal principles) and ontology (material principles). ${ }^{11}$

Absolutist and relativist conceptions are useful for introducing another, perhaps deeper pair of distinct metaphysical behaviors: prescriptive (or corrective) and descriptive ones. ${ }^{12}$ What is the task of metaphysics? Does it have to do with examining the world and offering arguments for or against the existence of a category of objects? Or does it have to do with collaborating with others to try to bring order and conceptual clarity to a predetermined discourse, whose truth does not depend on metaphysical judgment? Let us take, for example, the case of a scientific metaphysician and eliminativist who believes that the world is made of physical atoms. According to this perspective, people, sheep, cows, pines and figs don't exist, and books, oceans and the sun also do not exist - the only thing that exists are clouds of atoms that move at great speeds. We are talking about a prescription-the large majority of people "believe" that all of those things exist, but if they reflected on it with the right attitude they would understand that their beliefs are not founded. Philosophically speaking, the task of this metaphysics consists precisely in explaining why the majority of people are wrong. On par with this metaphysics, when we sometimes find ourselves discussing specific metaphysical problems, we would like to say that things must be a certain way-cows must have

11 On this distinction see also Varzi (2005), chapter 1.

12 This question is taken on by various other authors, among whom is Varzi (2001), 28-33. 
a soul, the mind must depend on the brain, an event must have a cause. In these, as in similar cases, we are doing "prescriptive" or corrective "metaphysics." On the contrary, "descriptive metaphysics" is not a corrective approach with regard to a precise vision of the world. The objective, contrastingly, is to shed light on fundamental principles upon which we organize reality, assuming their truth within the specific realm of discourse. Let us suppose that we must collaborate with the person in charge of the marketing for a large store to more deeply understand the structure of that reality. Our task would not be to negate the existence of cookies or shirts in favor of atoms or strings, but rather to clarify the criteria under which the products are subdivided within the categories and systems of the various shelves, or to reflect on the subdivisions of space and the way in which this is received by the consumers. The risk is that this approach may produce an analysis of the situation which is not sufficiently critical and therefore not effective. Also, a classification of products in a supermarket (for example) responds to specific practical needs for which there will be good and bad solutions, and presumably it will be true or false that a certain metaphysical principle can contribute appropriately, or not, in distinguishing a solution. Analogously, in responding to questions like "what is a recipe?" or "what is blues?" it doesn't seem possible to elaborate a simple description of recipes or blues riffs. A "normative" component is necessaryboth recipes and blues riffs must exhibit certain features, otherwise they would not be what they are.

Before moving on, note that the metaphysical approaches dealt with until now are not only applicable with regard to general theories of reality, but are also useful with respect to specific domains. The metaphysical problems that we deal with are often local. On September 11, 2001, in lower Manhattan, were there one or two terrorist attempts? Are a genetically modified tomato and its non modified "progenitor" of the same species? Is a Florentine steak a natural or artificial object? What is the relationship between Marilyn Monroe and her body? Some philosophers - including those writing here-prefer to begin with local problems when dealing with a large part of contemporary metaphysical issues. From this perspective, it is possible to think of a form of metapluralism, or rather a position of metaphysics that, according to the question at hand, adopts a specific metaphysical behavior (eliminativist, reductionist, pluralist etc.). From these premises we may begin to examine the principal ideas of metaphysics, beginning with existence.

\subsubsection{Existence}

What exists? Everything, you might say. As Quine 1948 pointed out, if we say that there are things that do not exist we seem to fall into a contradiction or 
we involuntarily support a bizarre metaphysics like that elaborated by philosopher Alexius Meinong, according to whom some things are but do not exist. Clearly, we have innumerable ways of refusing the everything which exists. In the preceding sections we traced out some criteria that help to map out what there is. There are other positions that deserve to be remembered for their historical importance. ${ }^{13}$ The Platonists hold that everything that exists is able to be subdivided into two fundamental categories: material and ideal entities. The first includes everything that exists which has a historical boundary, or rather is tied to precise points within a spatio-temporal network; for example, think of how the life of a rose is limited by a precise temporal organization. On the other hand, the ideal entities are independent of the way in which they are spatio-temporally linked; numbers, geometric figures, meanings and, according to some, the soul or spirit are a few examples of this. Materialists retort that all that exists depends on that which is material- there are no souls or spirits, numbers, figures or meanings that can give sense to the existence of a material object. Because of this, ideal entities depend on material ones. The Platonists would object that the dependence of the ideal on the material is accidental, while that which is ideal has ontological priority in relation to that which is material. The number twenty-seven is not identical to any of its inscriptionson the contrary, the inscriptions of twenty-seven are what they are in virtue of the existence of the number. We are talking here about an ancient dispute that goes back to the origins of philosophy.

How might we explain the meaning of "existence"? In the Western tradition this question has received a multitude of responses. For the Platonists, existence had to do with different degrees of perfection, and the same can be said of people, films, sports cars and so on. This position was privileged until at least the time of the Renaissance and was taken up again in the 1900s thanks to Being and Time (1996) by Martin Heidegger. In the meanwhile, another view had been gaining ground, according to which "existence is not a predicate." This is one of the central theses of modern philosophy and logic and was already formulated in Kant's Critique of Pure Reason (1998). According to this thesis, existing is neither an activity nor a quality, and it does not mean doing something or being a certain way. When a person affirms that something exists, he or she is simply saying that the thing enters into his or her realm of discourse. This point has also been expressed in more rigorous terms, through a language of logic, by saying that "existing" means being part of the realm within which the quantifiers of language range, or rather, to be one of the possible

13 On the dispute between the Platonists and the Nominalists, cf. also Varzi (2005), section 3.1.1. and Varzi (2001), chapter 7. 
values assigned to a variable which is constrained by a quantifier (cf. infra ch. 4.4.4). Notice that the thesis is about "existing" and not "living." The term "living" seems to express an activity-living beings and non-living beings are distinguished by what they do, like metabolizing and self-reproducing. Saying that the dog Fido exists is different than saying he is alive. In the first instance we are simply saying that Fido is a part of the all, and in the second case, we are saying, among other things, that Fido metabolizes what he eats and has (or could have had) the capacity to reproduce.

\subsubsection{Identity}

When talking about identity in metaphysics one could mean strict identity, also called numeric identity, or rather generic identity. Two identical twins are identical in the generic sense-they are not the same in all aspects (typically not even genetically), but they look a lot alike. Analogously, if we find ourselves at a reception and we need to choose between two cans of Chinotto on the table in front of us, we would say that it doesn't matter which one we take because they are identical, but, obviously, we don't mean that they have everything in common. On the contrary, those who sustain that the mind is the same as the brain mean to say that they are the same thing, like when, to explain the plot, we say that Clark Kent is Superman. We are talking about a strict identity.

The primary doctrine of strict identity is often said to be that everything is identical to itself and to nothing else. The way to specify this slogan, in perhaps a more clear way, is to use the so-called "principle of the indiscernibility of identicals" that dates back at least as far as Gottfried Leibniz. This states that if $x$ and $y$ are identical, then they have the same properties. This principle, at first glance, appears airtight. And yet, in a recent metaphysical debate this claim was put into discussion. ${ }^{14}$ For example, take a cracker and consider its right half and its left; from one side, it seems clear that the cracker has identical halves, and yet the cracker is one whole while the halves are two. Or consider a soccer team and its players during a game-in as much as one would think that they are identical, the team competes for a championship, but the players who lead the team to victory do not. Finally, one will see that the principle of the indiscernibility of identicals must be kept separate and distinct from its converse, the "principle of the identity of indiscernibles," which states that if every property of $\mathrm{x}$ is also a property of $\mathrm{y}$, the two are identical. This principle seems even more suspect and is often refuted by metaphysicians. ${ }^{15}$

\footnotetext{
$14 \quad \operatorname{Varzi}(2001), 65-66$.

15 Cf. Varzi (2001), 96-130 and Loux (2002), 97-101.
} 
A separate case has to do with diachronic identity, or rather the identity of a body through time, as was discussed by Aristotle and also by a large number of the classics of Western metaphysics. The fundamental idea is that every living organism is the product of a process of development during which the organism inevitably changes. Every human being, for example, starts from a fertilized cell and develops into a complex system that includes billions of cells which specialize in different tasks. It is common practice to speak about a human being as being the same throughout the entire arc of his or her life, but are we referring to a strict identity or a generic one? According to one line of thought, ${ }^{16}$ that of the so called "endurance theorists," we are dealing with a particular case of strict identity. In the diachronic case, in fact, identity is not governed by the principles of the indiscernibility of identicals but by a weaker version of the principle. The so called "perdurantists" retort that we are dealing with a case of generic identity, and that during each instant of the life of the organism we have a new individual which we generically consider the same in virtue of the similarities and the causal relationship with its previous stage of development. Every stage is a part of the entire individual, and it configures itself as a quadridimensional entity. The organism refers to the entire succession of individuals which are causally linked and similar. The dispute between the endurantists and the perdurantists, with relevant facets which we cannot elaborate in this forum, has been, in recent years and even today, the center of an intense debate in analytic metaphysics.

\subsubsection{Individuals, Events and Properties}

Existence and identity are based on entities, in whatever they may be, and because of this they determine certain formal characteristics of all that is. What are the chief categories into which we may subdivide that "all"? We will start from the most common and basic - the individuals. They may be considered the "protagonists" of Western metaphysics. With the exception of some events like a sea storm or a soccer championship, everything that exists is, at least in the common sense, a way of being for some individual. Human beings are themselves individuals and can be used to exemplify the category. Giuseppe Garibaldi was an individual. There have been many similar leaders, but none of them was Garibaldi. The day Garibaldi died, he was no longer an individual. Garibaldi, therefore, was one, though according to some he wasn't by virtue of his properties. We might think of reproducing an individual indistinguishable from Garibaldi (completely identical in all respects) and yet even that would not be Garibaldi.

16 On the distinctions that follow see also Varzi (2001), chapter 5. 
Properties are, on the other hand, that which gives an entity (including an individual) its way of being. Garibaldi's beard was one of his properties, just like his being courageous or Italian. But properties are also the basis for events, a category which is often contrasted with individuals; with the exception of goals (for example the reaching of a peak or summit) an event has a diachronic development and it is not necessary that it be countable. The wind, an earthquake, a concert - these are all examples of events, the first of which does not seem countable. Even events have properties - wind might be hot and intense, an earthquake minor, a concert long and engaging.

A classic metaphysical problem, posed first by Plato, deals with the relationship between properties and the entities that, one might say, "instantiate" them. ${ }^{17}$ According to one reading, if it is true that Socrates is wise, meaning that there exists a relationship R1 between the individual Socrates and wisdom. But, one might ask, what makes this relationship link wisdom to Socrates? If we say that $\mathrm{R} 1$ is linked to wisdom because of a relationship R2 and to Socrates because of another relationship R3, we might ask what links R1 to R2 and to wisdom, on one hand, and R1 to R3 and to Socrates on the other; and so on. For this reason, some authors have preferred to maintain that properties do not exist: this position is called nominalism and its more sophisticated formulations can be found in the late medieval period in works by authors like William of Ockham and John Buridan. Others, on the other hand, maintain that the above problem can be circumvented by adopting a wary theory of instantiation. This position takes the name "realism" and includes a large part of Western philosophers, including high caliber names like Aristotle and Thomas Aquinas. A third, larger group maintains that the individuals must be, metaphysically speaking, eliminated, that properties are all that exist. This position is called "universalism" or "tropism" depending on whether the properties are considered as universals or tropes. In the first case, the different instances of a property are considered numerically identical and, at the same time, multiple. For example, the electric charge of an electron is numerically identical in every electron and this explains their perfect resemblance. According to the theory of tropes, on the other hand, the different instances are numerically distinct, even though they enjoy a primitive resemblance (not reducible, or not sharing other properties). The charge of an electron is distinct from that of every other electron, despite the fact that there is a perfect resemblance between the two (which is not otherwise definable). The dispute between nominalists, realists, universalists and tropists is one of the most lively and complex within metaphysics, and not just Western metaphysics.

17 For the distinctions that follow cf. Varzi (2005), § 3.1.1. 


\subsubsection{Types of Properties and Relations}

If it is the task of metaphysics to study the structure of reality, one of the key instruments for being successful in the endeavor is to take advantage of an adequate range of properties so that one might subtly distinguish between the typologies of individuals and events. In short, there are properties and there are properties. Here we will consider four of the most important types of properties, and then we shall conclude with a brief note on their relations. ${ }^{18}$

Saying that Azrael the cat is alive is very different to saying that he is cuddled up. While Azrael could very easily stand up and continue to exist, the cat could not stop living without ceasing to exist. (Naturally, depending on the point of view, it is perfectly acceptable to say that the body of Azrael would continue to exist, and that Azrael, all the same, would no longer exist.) In other words, while being cuddled is an "accidental property" of Azrael (the cat could easily have stayed on his feet), being alive is an "essential property." If he lost this property, he would simply cease to exist. A property is essential for an individual when the individual maintains that property in all possible situations. Contrastingly, a property is accidental when in at least one situation that individual loses or gains that property without ceasing to be. Essential properties of an individual are therefore properties that are necessary for the individual's existence. According to a certain essentialist tradition, then, essential properties are the properties that define the individual. Aside from being necessary for the existence of Azrael, therefore, "being alive" would also be a part of his definition (some contemporary authors, indeed, take care to tell apart necessary and essential properties - only the latter defines an individual). This should not be confused with the (hardly credible) thesis which purports that an essential property is "sufficient" in itself to maintain an individual's existence.

Also relevant is the distinction between "simple" and "determinable" properties, a transverse operation with respect to the one we have just seen regarding accidental and essential properties. A property is simple when either you posses it or you don't. "Being an Italian citizen" is a simple property; there is no in between-either you are an Italian citizen or you are not. A determinable property, on the other hand, allows for gradations based on a certain scale. For example, "being a color" is a determinable property within the color wheel,

18 Useful to consult for the elaborations that follow, aside from the cited introductory texts by Varzi (2001) and (2005), see the philosophy dictionary by Floridi and Terravecchia (2009). 
and "being a certain weight" is a determinable property within a certain scale of measurement.

A third distinction between "atomic properties" and "structural properties" perpendicularly cuts the two properties just mentioned. As we know, water is a compound element, and its chemical structure is (at least partially) schematized within the formula $\mathrm{H}_{2} \mathrm{O}$. Let us take the property "being a water molecule," which belongs to all that which is water and to nothing else. "Being a water molecule" would be a structural property, precisely because it characterizes all of and only certain structures, i.e. those which contain two exemplifications of the property "being hydrogen" and one exemplification of the property "being oxygen," related in a certain way to become a certain qualitative structure. Other examples of structural properties include "being a vertebrate," "being a heart," "being a cell," and also "being a car," "being a cigarette" and "being a watch." On the other hand, atomic properties are those which have no structure. The concept is as easy to explain as it is difficult to find examples. At one time, it was believed that atoms were, dare we say, atomic. Later, electrons and protons were seen as atomic, then quarks ... in essence, there is a continual discussion about what the "truly" last individuals and the "truly" atomic properties are. But we may also cite some cases that do not stem from the natural sciences. So, the properties which are characteristic of certain colors, like "being white" (if we understand whiteness as a perceptive property) are atomic, and some maintain that fundamental properties in ethics and aesthetics, "goodness" and "beauty," are also atomic.

Lastly, let us cite a distinction between "intrinsic properties" and "extrinsic properties" which has been at the center of numerous debates in recent years. Approximately speaking, an individual possesses intrinsic properties independent of the context in which they find themself. The form of a triangle, for example, does not depend on the context in which the triangle is found, unlike its distance from a circle; this distance would be an extrinsic property.

Before moving forward let us mention an equally important theme- that of the relationship between individuals. Among these relationships, some of the most important are spatio-temporal relationships, the relationship of ontological dependence (for example, a group does not exist without its members), the relationship of occurrence (for example, there could not be a difference in our thoughts without there being a difference in our mental states), and the relationship of causality. We cannot deal with each of these separately, but you will notice that, despite the fact that in metaphysics relationships are often considered analogous to properties, they present unique difficulties. Firstly, since the instantiation of a relationship involves two or more individuals, the 
modalities within which the relationship takes place should be clarified: is a relationship like a bridge that rests on the two individuals involved? Or does it exist separately in each of the individuals? In this last case, what links the elements within the relationship? Furthermore, do all relationships "link" individuals or events in analogous ways? Causality and spatio-temporal distance, for example, seem to be distinct enough to suggest that a metaphysics of one could not hold for the other.

\subsubsection{Possibilities and Necessities}

The method with which we conceptualize the structure of the world is crucial for how we operate within it. The ideas that we have saved for last are, perhaps, from this perspective, the most important. We are talking about the possible and the necessary, which are technically called "alethic modalities." The term "modality" is used because a modal expression characterizes the "mode of existence" of the entities to which the expressions it applies to refer. Let us consider, for example, the utterance "Rain" and its variants: "Today: it rains"; "In Manhattan: it rains"; "I believe that: it rains" "It is (morally) good that: it rains"; "Necessarily: it rains"; "Possibly: it rains." Each of these variants expresses a way of being of rain, or rather a way of being of the entity to which "Rain" refers. The "alethic modalities," from the Greek $\dot{\lambda} \lambda \hat{\eta} \theta \varepsilon ı$ (álétheia) or "truth," specify the "mode of being true" of the entities to which the expressions refer and are applied. Possibility and necessity are alethic modalities. The modality of the possible is used to express the fact that the existence of an entity may come to be; the modality of the necessary is used to express the fact that, no matter what, it will come to be (Cf., infra ch. 4).

Now, the majority of possible entities are not actual; they never concretize themselves in our universe. We are talking about entities with which we cannot have direct experience. I can know that Fido the dog is crossing the street because I am witnessing the scene. I can know that yesterday Fido ate milk and cookies because Elena told me so, and she witnessed the event. But how could I know that Fido could have eaten milk and cookies today too, or what if he ate fish and potatoes instead? Neither I nor anyone else ever witnessed Fido's lunch. Maybe this possibility is pure invention, or a projection of our minds. Or maybe it is an induction, or rather an inference made because of certain empirical data. Might we infer that Fido could have eaten milk and cookies today based on the fact that he ate milk and cookies yesterday? Or, it is a deduction, an inference based on a purely logical reasoning. Could Fido have eaten milk and cookies today because there is no contradiction in this thinking? These questions raise "the problem of possibility" — what does it mean to 
say that a certain situation is possible? Are there metaphysical facts that justify our beliefs about what is possible or necessary?

The problem of possibility is more complex than it appears on first sight. Remaining within its metaphysical aspects, one might ask "what is a possible entity?" There are eight differing positions here (for details see Borghini 2009). Some refute that alethic modalities express concepts, either because we are not able to truly understand the thing of which we speak (skepticism), or because what is really in question here are feelings and not concepts (expressivism). The other positions, on the other hand, maintain that the task of a theory of possibility is to explain modal concepts. Among the positions which maintain that the dispute is a conceptual one, some (the modalists) believe that alethic modalities cannot be analyzed in terms of other concepts. There is no clearer way to explain the expression "Napoleon could have won at Waterloo" than to say that "Napoleon could have won at Waterloo." Others, instead, have tried to explain modal concepts. Some (modal realists, ersatzists, fictionalists, agnostics) all make use of the semantic theory of possible worlds, a theory formulated in an appropriately formal language (and therefore not natural), meant to express certain conceptual relations between alethic modalities in the most rigorous way possible (cf. infra ch. 4). Others (the dispositionalists) make use of concepts of availability, the capacity of a being to act in a certain way if placed in some conditions. What to say of the necessary? - all that which does not belong to the realm of the possible is necessary. But, one could ask, once we have a theory of the possible, will we also know how to take account of the impossible? In part yes, in part no. Once an interpretation of alethic modalities is established, we will know where the boundaries lie between what is possible and what is impossible. Nevertheless, this does not mean that we will know how to deal with questions that emerge when we begin to take impossible situations into consideration. If two plus two equaled three, then this afternoon could I go surfing on twenty-seven surfboards at the same time? Or, can we allow for an impossibility without having to compromise the truth of other things that we think?

\section{$1.2 \quad$ Things that Exist}

Ontology, a bit like aesthetics (infra, ch. 9), is a discipline that boasts a long history, and existed long before its disciplinary foundations. It was Johannes Clauberg, an ontologist from the 1600s, who used the term in its fullest degree in a work entitled The Elements of Philosophy, that is, Ontosophia (1647) in 
which he conceived of the study of ontology as the study of entities as such, or in as much as they are intelligible. Ontology and metaphysics are related in Clauberg as forming a binomial that since then has never been abandoned, ${ }^{19}$ though the modalities of this relationship will greatly vary (cf. supra, § 1.1.0.). Clauberg clearly separates ontology from metaphysics, underlining how ontology belongs to the domain of entities in the more general sense. In this sense, ontology deals with that which is and that which exists.

To follow the theoretical tracks which tie ontology to metaphysics in contemporary philosophy we must address the divergences between the analytic tradition and the continental one which, here more than in other places, entail choosing a position in regard to the task of philosophy itself. Much more than has taken place in the analytic field, continental philosophy proceeded from a place of substantial contiguity with theology. For example, in Martin Heidegger's case, in his most formed reflections, he considered ontology to be a form of theology, since it had much to do, if only negatively, with God. This should not be surprising if we maintain, with Heidegger, that the true being, the authentic being and not the hidden one, is precisely God. So within the Heideggerian system, ontology becomes a theology of the divine entity (Heidegger 2002), which is carried out starting which a subject whose thinking begins from a world. In Being and Time (1996) he develops an analytics of existence beginning precisely from the dispute wherein that which exists starts from concrete existences that are located within a specific space and time, as well as within a determined historic "opening."

This essentially means two things: firstly, that the entity, the object of ontology, substantiates itself in the true sense only if it is present within the judgment of the subject that knows it. Secondly, it means that the "opening," or rather the historic dimension to which the subject belongs, is decisive in the being's production of self-meaning. This means that not everything is accessible in any given historic moment; for example, the Greeks could not have understood the concept of "universal gravitation" because it simply could not have appeared in their world, but also and more specifically it means that only those things exist which are accessible to the subject given the subject's historic perspective and within the holistic structure that comes from the world in which the subject finds itself (Heidegger 1992). Things come to be, or exist, not only, and not so much, in the moment in which they become the object of our experience, which exhibits characteristics of "unchangeability," but rather when the historic opening in which we find ourselves allows us to

19 For an historical excursus we refer to Ferraris (2003) and (2008, 113 et seqq), above all with reference to the history of the term. 
understand them. In as much as Heidegger was careful to keep a distance from psychologism (1978) and to reassert that the historic opening is governed by the structural references of meanings in which we find ourselves, it is moreover evident that the reflection on that which there is, depends largely on the historic moment in which it is carried out. The distance from here to the superhistorical being that founds the entity that we ourselves are is not far, in fact, and Heidegger makes sure to do just that in the last phase of his work (cf., for example, Heidegger 1982).

If it is obvious that a theologian deals with the supreme being, identifying them with God, and attempting to solve the questions that deal with his possible existence, then the choice is less evident for the philosopher. In other words, wanting to work on that which exists, it is reasonable or at least prudent to decide to suspend judgment with regard to God and his existence in order to remain within the world and within the entities which compose it. This holds as long as we intend to remain within the realm of philosophy.

Historically, investigations within the ontological field have assumed very diverse characteristics and traits that are as different as the terms of the relationship between ontology and metaphysics.

A good way to read ontology and its relationship to metaphysics is by following the method started by Edmund Husserl (1975). He distinguished "formal ontology" that speaks of the being in general-the ontology that in these pages we have identified with metaphysics (supra, § 1.1.) - from "material ontology" which, instead, deals with the diverse and specific realms of reality. Within this realm regional ontologies of math, physics, biology, art and the social world have been developed and, in very recent years, even ontologies that call into question common sense and basic knowledge. Before getting into regional ontologies it is worth speaking briefly about the metaphor of the "catalogue," used as a sort of underlying thread linking contemporary thought.

\subsubsection{On Catalogues and World Maps}

The question that guides inquiry in ontology is "what is there?"; also, to give a more general formulation "what exists?" Formulated in these terms the question seems banal, since the answer risks being virtually impossible. Luis Borges has tried to imagine an answer in The Analytical Language of John Wilkins (2000), or rather he put his answer in the mouth of doctor Franz Kuhn, the clever pedant, who makes a Chinese encyclopedia with the phantasmagoric title Celestial Emporium. What do we find in this emporium? Let us read an excerpt of Borges' text: "animals are divided into: (a) belonging to the emperor, (b) embalmed, (c) tame, (d) sucking pigs, (e) sirens, (f) fabulous, (g) stray dogs, (h) included in the present classification, (i) frenzied, (j) innumerable, 
(k) drawn with a very fine camelhair brush, $(\mathrm{l})$ et cetera, $(\mathrm{m})$ having just broken the water pitcher, (n) that from a long way off look like flies." With this bizarre and improbable encyclopedia Franz Kuhn gave life to the dream of all knowledgeable beings, mapping out an inventory of all that exists; an inventory that includes everything, from the most important things to the most trivial. The mania of collecting? Not only that. It is known that God, or someone representing him, is hidden in the details and doctor Kuhn had to have thought that the most trite detail, capable of being missed by the encyclopedia, could hide that fold that opens different comprehensions of the world. The worries of doctor Kuhn, and with him pedants of all times, are to be kept in consideration for two reasons. The first involves historic reasons-I cannot speak of something that is there if I do not know it first. The second has to do with practical reasons - we cannot think of leaving a mark on the world, or rather of determining our actions based on a particular scope, if we do not know how the world in which we move around is made.

Making the inventory ${ }^{20}$ of things that exist is a fairly complex operation. Meanwhile, it is worth questioning the method.

To do so, we can refer back, once again, to Borges who, aside from imagining weird catalogues, tries to also ask himself what use we would have of a map with a 1:1 scale. A map of this type would serve very little given that it would end up coinciding with the reality that it seeks to map, therefore it is better to choose and illustrate or exemplify if we want the operation to be useful in some way. In other words, and to put this in more complex philosophical terms, the strategy of Willard O. Quine (1908-2000) will probably not help us very much, as he responds to the ontological question with disarming simplicity: "What exists?" simply "everything" $(1948,3)$, as it does not make sense to speak of nonexistent entities or that which does not exist, or rather that which does not have a form of existence within the space and time; in some way it exists, otherwise we could not speak of it.

Quine's answer leaves nothing out, and yet it is too vague, precisely because "everything" is not very useful for solving our conceptual problems. A more detailed answer would be more useful. In other words, it is necessary to specify what we mean by "everything." We do not need to list, one by one, all the elements that make up the world, but we do need to point out all of the structural elements that make it. And, in wanting to consider these things from closer up, we realize immediately the difficulties we are up against. We do not have any doubt of the existence of many things: houses, mountains, trees, flowers,

20 Cf. Broad (1923, 242 et seqq) on this theme, and more recently, Varzi (2001) and Ferraris (2012). 
animals ... we could continue to expand this list for quite a while. However, the first snags are multiple and right around the corner. They have to do with, for example, the existence of some objects. As I write, my shadow is projected onto the ground. Does that shadow exist, or is what I see simply an effect of the blacking out of the light from the sun? I love five o'clock tea which, generally, I take with a donut, and donuts, we know, have a hole in the center. What is that hole? Does it really exist, in our inventory do we need to include things like holes, or is it simply some material taken out of the donut and the holes, themselves, do not exist? Let us reflect upon this further - are we really sure that they do not exist? And what about the holes, or rather deficits, in a overdrawn bank account? Do they not exist or are they the things that exist most in the world? At least in terms of the consequences, we know that they carry harsh ones, and so, perhaps, they exist. And if they exist probably we should include them in our catalogue. Admitting that they exist, what form of existence do they then have? Having said that, the problems linked to existence, or to the forms of existence, are certainly not the only ones to be considered. Intuitively it would seem that the firmest ground for simple classifications is the one constituted by material objects, while the more the objects lose their physical consistency, the greater our difficulty in classification. In reality this is true only in part, since objects which have material consistency and existence in space and time are not without their problems of classification. We could have problems with identity and persistence in time. An example? Let us think of a contemporary example from the mental experiment of the ship of Theseus thought up by David Hume. In our slightly noir and postmodern version, we find a mad scientist, or maybe just one with uncertain ethics, who works on creating a new Frankenstein. Let us imagine, therefore, that the scientist substituted, following a methodic plan, the body parts of the subject of the experiment (both internal and external), with corresponding artificial parts, or parts taken from other bodies: a heart, liver, lungs, eyes, skin, ribs, hair.... Up to what point can we consider the body a natural object? Up to what point does the person, who was that body, remain the same? On the other hand let's think more banally of the memories that make up our lives. They play a fundamental role in our personal identity. How many memories can go lost, and how many must be preserved for me to still be myself? Let us think of cases where people wake from comas; the physical identity is preserved, but the memories are inexorably lost forever. In other words, how many variations can a body or a being undergo before it becomes something else? Locke solves the question in an elegant way-personal identity circles around a string of memory. If this is so my brain could be implanted in another body - no one would recognize me, at least in the beginning, and yet I would still be myself. So, do people not 
coincide with their bodies? Let us look at another case. Which one of us would not introduce works of art into our catalogue? It is not even a discussion that they exist - if we owned a work of value surely that hole in our bank account would scare us a lot less-yet the ontology and philosophy of art both know how many and what the problems tied to defining a work of art are ${ }^{21}$ (infra, ch. 9). For example, are we really certain that we recognize a work of art when we see one? Constantin Brâncuși, Andy Warhol and Dan Flavin are three wonderful and involuntary examples of what we are talking about. We are in 1926 and the protagonist of the story is Constantin Brâncuși. Bird in Space arrives at U.S. customs accompanied by its creator and Marcel Duchamp. The project was to exhibit the work in a New York gallery. During the usual control, the customs officials, given the job of classifying the object to apply the correct taxes, mark it as a kitchen utensil despite Brâncuși's protests. The artist took the case to federal court. After a heated debate, the court declared that Bird in Space was a work of art though it didn't look anything like a bird.

Let us go to the second example. We are in 1965, the protagonists are Andy Warhol, the Canadian customs agents and the Brillo Boxes that were supposed to be exhibited in a local art gallery. The customs agents classify them as general store objects, and how could they be considered wrong when, at that time, boxes of Brillo, filled with rough sponges to wash pots and pans, were all over the supermarkets of North America? ${ }^{22}$ As might be imagined, Warhol also protests and so the Canadian government asks the opinion of an expert. Mr. Comfort, the director of the National Gallery of Canada, instead of taking the side of Warhol, supports the decision of the customs agents. Brillos are commercial objects and should be taxed accordingly.

Let us now turn to recent news. We are in December of 2010 and the protagonist is Dan Flavin, or should we say, his work. Icons crosses the ocean and arrives in Europe. This time it is up to the European Community to express itself: Flavin's Icons are lights and types of light fixtures, and are therefore subject to a corresponding tax that is much higher than that assigned to works of art. General store boxes that are almost indistinguishable from works of art, works that are mistaken for kitchen utensils and arranged light fixtures, are all works displayed in museums, while other lamps and chandeliers that we find in those same museums are useful only for giving light. A real conundrum, for sure.

21 For a detailed investigation of the question cf. Carroll (1999) and Andina (2013).

22 About these questions cf. Danto (1981), (1997) and (2003), a trilogy of texts indispensable for understanding the Dantian philosophy of art and its implied ontology. 


\section{$1.3 \quad$ Regional Ontologies}

Unlike metaphysics which is concerned with individuating the structures of reality in general (therefore, virtually everything real or possible), regional ontologies $^{23}$ are concerned with explicating the structure of that "something" that characterizes the specific regional area in question. More simply, the ontology of mathematics deals with mathematical entities, the ontology of physics deals with the physical world, the ontology of biology deals with the living world, and so on. ${ }^{24}$ As our main example we will examine a particular domain, one to which contemporary ontology has dedicated specific attention-social ontology.

\subsubsection{Social Ontology}

Social ontologists aim to define and describe the structures and the dynamics of the social world, or rather the part of reality that is not reducible to the physical world and was "built" by human beings to live-out desirably fruitful relationships of co-operation and exchange. Aristotle in his Politics noted how human beings are essentially social animals, or beings whose collaborative and public dimension is a constitutive part of their identity. It is precisely for this reason that ontology cannot free itself from the social world.

The components and actors within the realm of social ontology are essentially: (a) individuals as social agents, (b) groups (that maintain relations to other groups and with the State), (c) the beliefs and actions that have nonindividualistic characteristics, and finally (d) social objects, namely, those objects that are distinguished from natural objects, artifacts and ideal objects.

Within a structure of this kind, social ontology sets out to answer questions such as: "what is social reality?", "is it possible to conceive of a definition of social facts and objects?", "what distinguishes brute facts from social facts?", "what type of objects are groups?", or, to say it differently, "what are the conditions that allow us to consider a collection of individuals a group?", and, to explore the question, "is it possible to develop a constitutive rule of social reality?” In The Rules of Sociological Method (1964), Émile Durkheim significantly warns scholars of social reality against the regular use of ordinary language within a discipline focused on common sense. So an important aspect in correctly defining the methodology of the discipline involves the terminological clarification of concepts (cf. Lewis 1969; Gilbert 1989).

23 The study by Bottani and Davies (2007) is dedicated to the particulars of regional ontologies.

24 For greater depth regarding the other directions of research cf. Ferraris (2008). 


\subsubsection{The Bases of Social Actions: Alessia's Walk}

Following Margaret Gilbert (1996, 177-194), let us consider a very normal scenario, which we shall call "Alessia's walk." Let us suppose (case 1) that Alessia decides to take a walk. Alessia decides to go out by herself, along a set route, and she is joined by Marco, whom she knows. Let's say that Alessia does not seem bothered and that Marco, after saying hello to her, says "I would like to walk for a while with you" and that Alessia responds: "Me too! Let's walk a bit together."

Let us now consider a variation of the same scenario (case 2). Alessia and Marco, during a brief telephone conversation, decide to go for a walk together. They decide the time of their meeting, the route they will take and the destination. That afternoon they set off on their walk.

The differences between the two scenarios are minimal, but important and make up the difference that separates a singular action from an action that has social ties and characteristics. Let us examine them. In the first scenario Alessia decides to go for a walk by herself, her meeting with Marco is accidental and it does not require the two protagonists to perform any joint action. The two together carry out a bit of their walk that they had previously decided to carry out alone. The conditions of the second scenario are different from the start. In fact, in this case we have:

(a) an objective planned out together ("the walk")

(b) the desire of both parties to reach their predetermined goal which is manifest through the actions of both Marco and Alessia.

Let us imagine that in both scenarios, after a bit of walking, Marco, who proceeds at a faster pace than Alessia, ends up distancing himself from her. Let us imagine this within the first scenario - if Alessia complains as she catches up with Marco, her lament would seem excessive. After all, the two of them met by chance, and by chance they decided to spend some of their walk in each other's company. So Marco is not obliged to wait for Alessia, nor is he obliged to worry about her. Things go differently, as Gilbert claims, if Marco distances himself too much from Alessia in the second scenario. This time, Alessia is justified in complaining to Marco, who should be thinking of her.

This happens because the two protagonists of the "combined action" (going for a walk) have explicitly and jointly defined a valid goal for both of them, and each is responsible for carrying it out. Furthermore, both have the proper awareness for achieving their end goal-in our case both Alessia and Marco know what it means to take a walk, they know the reasons for which two people decide to accompany each other for a bit, they know what it means to walk 
"together," and so on. Marco, however, does not behave in a way that is in keeping with what is necessary - both of them arriving at the destination — and for this reason Alessia is permitted to chastise Marco with respect to the previously stipulated agreement.

Therefore, if one of the two players fails to achieve the shared objective or does not do all they are capable of doing to insure the objective is reached, this constitutes sufficient grounds for one of the involved parties to consider the other a defaulter and, in the most serious cases, the mutual pact is depleted of its initial meaning. This fact determines the suspension of the tie that binds Alessia and Marco.

We are not talking about a moral tie (Gilbert 1996, 181), but an ethical one whose existence is independent of any juridic system. It is always possible that two people who, hypothetically, do not use concepts of obligation and moral law, decide to take a walk together and they do it without breaking the principles that advise a person to care for the other for the benefit of reaching the common goal. A principle of "cautiousness" advises Marco to take care of Alessia, since this is the most advantageous choice for the "we" formed by Alessia plus Marco.

\subsubsection{The "We" as Plural Subject and Its Beliefs}

From here we reach Gilbert's powerful idea of the pronoun "we," the indicator par excellence of social action, an authentic subject, something ontologically different from the sum of single individuals. In other words, the "we" that emerges from the choice of Alessia and Marco to walk together, forms what Gilbert defines as the "plural subject" (1989, 306 et seqq); it is not just a mere sum of two individuals (Alessia and Marco), but a new subject that does not share all of the properties that we can ascribe to Alessia and Marco taken separately and singularly and is meant to respect the ties that neither Alessia nor Marco are obliged to respect. In addition to assuming a plural dimension in the exact instant in which they sanctify their pact, Alessia and Marco are and remain singular subjects with beliefs, desires and hopes that they are not obligated to share. Gilbert defines the "plural subject" in this way: "when a goal has a plural subject, each of a number of person (two or more) has, in effect, offered his will to be part of a pool of wills that is dedicated, as one, to that goal" $(1996,185)$. The tie that unites the individuals who decide to be part of a specific plural subject is of a particular nature. It does not have to do with a bond that comes from a promise, but a bond that is subordinate to reciprocal respect for the conditions posited and accepted at the moment of the elaboration of the common goals. It is a tie that imposes obligations and rights and remains valid as long as both parties actively work towards it. Alessia and 
Marco are tied together by their pact on the condition that each of them keeps it alive. It goes without saying that a tie of this kind is not cancellable by each of the parties involved in the same way, but the tie could be broken and the pact voided if one of the two parts is lacking in their actions toward reaching the common objective. In this same vein, Gilbert maintains that the beliefs of plural subjects do not come from the sum of the beliefs of the individuals, but are themselves ontologically distinct objects with respect to the beliefs of the individuals. From this perspective the beliefs meet two conditions:

(i) A group $G$ believes $p$ if and only if the members of $G$ jointly accept $p$.

(ii) The members of group $G$ jointly accept $p$ if and only if it is common knowledge in $G$ that the individual members of $G$ have openly expressed a common conditional tie to accept $p$ with the other members of $G$ (Gilbert 1996, 204-5).

\subsubsection{Institutions and Institutional Facts}

The idea that drives Gilbert's work, and was also the Leitmotiv of the reflections of Max Weber and Durkheim, is that the components of the social world (the actors, the values and the beliefs) constitute a separate reality that must be investigated. The same holds for the two central elements of social realitysocial institutions that, together with the acts they produce, are components of social reality, and social objects.

The theory John Searle articulates in The Construction of Social Reality (1995) seeks to capture the peculiar nature of institutions and social facts. He says that it is through these institutions and facts that we can understand the procedural nature of social reality, and later derive the notion of social objects from them (Searle \& Smith 2003, 301-3). In The Construction of Social Reality, as in later writings that elaborate on and discuss the principle theoretic core, ${ }^{25}$ Searle presents a theory of institutional and procedural nature. Such a theory draws large inspiration from the analogy formulated by George Dickie in the 1970s with reference to the ontologies of works of art (Dickie 1974 and 1977). ${ }^{26}$ The Searlian theory provides reasons for things like rights, commitments and obligations through the formula "X counts as Y in C" (1995, 82), where "X," in the simplest cases, refers to a material object or an event; "Y," in its imposition of a deontic power or a function on "X", in a context "C."

John Searle's social ontology is constructed on a double plain - at the base it connects brute facts, or rather, facts of physical reality, and on a second level,

25 Cf Searle (2010).

$26 \quad$ For a deeper discussion see Andina (2013). 
which emerges, so to speak, from the first, we have the social facts, which he calls "institutional facts." Institutional facts depend on human institutions and these, in turn, depend on a rather mysterious entity that Searle defines as "collective intentionality." To be clear, the existence of Monviso is a brute fact, while the existence of the University of Turin is an institutional fact. The theoretically sensible point has to do with, therefore, the path from brute fact to institutional fact (a subspecies of social facts), or the passage from physical object to social object. How does it happen that a piece of paper gains monetary value in a set context? ${ }^{27}$ What happens, as Searle tells us, is that on some material objects we place a function that renders these objects something different - a piece of metal can become a coin, and a canvas prepared with red lead can become a work of art.

Searle's objective is declaredly fairly limited - it is neither about elaborating a definition of social objects (in the end anything can be a social object, even a simple statement), nor is it about developing a general theory that explains social reality in its complexity. Instead, it intends to illustrate the functioning of the procedure that allows the change of status of the material object into the "social object."

So the correct question, from Searle's point of view, is not so much "how do we define a social object?", but rather "through what procedure can an X become Y in context C"? Furthermore, of his own admittance, the Searlian theory is limited to explaining the causes of institutional facts, that is to say the facts that are the products of institutions that have the power to produce them.

Without entering into details it is clear that Searle's social ontology, with all of its intricacies, rests essentially on five components:

(a) Physical objects

(b) Set cognitive acts in virtue of which some objects acquire a function different from their original function

(c) These same functions

(d) The context in which all of this takes place

(e) The entity called "collective intentionality" to which the task of the transfer of state is assigned.

Within this system there are at least three problematic points to this theory. As both Barry Smith (Searle \& Smith 2003) and Maurizio Ferraris $(2012,2014)$ note, the theory does not explain negative entities; in other words, those entities that do not depend on material objects. It is easy to show the point with

27 For a deeper analysis tied to the ontology of money cf. Turri (2009). 
objects such as money-what we save in our banks and what is available only as a "blip" on the computer, and the border line between the two states. Consider the cases in which the border is not marked by a physical object, but is an authoritative border, that is to say it is the fruit of a deliberation between two states. ${ }^{28}$ Furthermore, as Barry Smith emphasizes, in previously garnered criticisms against Dickie's institutional theory of art, ${ }^{29}$ the notion of context is opaque and should be clarified. Finally, an argument developed above all by Ferraris (2012) asserts that the notion of "collective intentionality" is a vague and problematic notion. Searle himself has acknowledged the mysteriousness of the notion:

Our aim is to assimilate social reality to our basic ontology of physics, chemistry and biology. To do this we need to show the continuous line that goes from molecules and mountains to screwdrivers, levers, and beautiful sunsets, and then to legislature, money, and nation-states. The central span on the bridge from physics to society is collective intentionality, and the decisive movement on that bridge in the creation of social reality is the collective intentional imposition of function on entities that cannot perform those functions without that imposition (Searle 1995, 41).

Having said that, it is not so easy to argue what collective intentionality absolutely is. It is not about the sum of individual intentionalities, but a capacity, a truly primitive capacity possessed by our species, as with other living beings, to "think in the plural," in other words to think of themselves as beings that are part of articulated and complex organisms (Searle 1983a and 1983b, 44950). It is precisely in starting from this disposition that entities like groups are formed, people make choices and carry out actions that are not exclusively individualistic, and institutions are formed to which we give a certain power (Searle 1995). In this sense, Searle can be seen as owing a lot to Gilbert and his analysis of the "plural subject." However, the most important difference is that Searle supports a "strong" hypothesis; this tendency to think in the plural would not stem so much from consolidated practices and from adaptive advantages, but it would have a real and true biological equivalent in the human brain. So this would: (a) not be reducible to single individualities; (b) be primitive, a fact that cannot be further broken down by analyses, in relation to individual intentionality, and finally; (c) have biological origins.

28 Cf. Ferraris (ontology of cell phones cite the example of Poland), and Searle \& Smith (2003, 287 et seqq).

29 Cf. Andina (2013, 43 seqq). 
This point is important because it allows the American philosopher to support a sort of automaticity in the formation of collective intentionality and, consequently, of the derived acts of these "collective-we's." It is different to maintain, as Gilbert does, that the beliefs and actions of the social world derive from the available capacities of living beings, but are not primitive since in order to exist they require the subject to carry out a specific job. This implies that the capacity to set goals and put the most apt strategies into action to carry them out is fundamental for the formation of the plural subject. In practice, the "plural we" of the Searlian hypothesis is a point of departure which is already present in our brains, while in Gilbert's hypothesis it is something that is reached after carrying out a certain task, ${ }^{30}$ which renders the theoretical hypothesis much less mysterious (Miscevic 2003, 265 et seqq). In normal occurrences this is the case, for example, in the changes of political regimes, where the dominant systems lose the consensus following a change of opinion on the part of the citizens. Individuals and their actions determine the birth of a specific plural subject that holds up as long as the agreement exists among the citizens, just as the actions put into effect endure in order to keep this agreement going. This would not be the case if collective intentionality was primitive and did not depend on the will of the subjects.

On the other hand, the physicalist and reductionist background of the Searlian theory is evident when he explicitly declares that he does not want to construct a social ontology starting from the objects of the social world so as not to incur risk-multiplying objects that are a part of it - a price that Searle does not intend to support - and where he instead elaborates an explanation of collective intentionality in terms of biological primitiveness (Searle 1983b). A social ontology built in this way is the tip of an iceberg that has its foundations in a certain metaphysics: "For me, we are all animals, biological beasts, we share with all sorts of other animals the capacity for collective intentionality, and with collective intentionality you get social facts automatically. For me a social fact is simply any case of collective intentionality involving two or more animals. Intentional facts are more interesting, because they involve a deontic component, and with that deontic component comes the requirement of language" (Searle \& Smith 2003, 304). The social objects, in such a framework, find justification in the explanation of social facts and their procedures, and in large part, they are all reducible to physical objects.

30 For a more detailed analysis cf. Miscevic (2003, 257-267). 


\subsubsection{Social Objects}

Maurizio Ferraris is of a different opinion as we see in Documentality: Why it is Necessary to Leave Traces (2012), when he proposes constructing social ontology starting from the examination of social objects. Adopting a generous ontology of Meinonghian inspiration, Ferraris develops his catalogue of the world starting from a fundamental tri-partition: "natural objects," "ideal objects" and "social objects" (2012, 32 et seqq). Social objects, just like natural objects but different from ideal objects, exist in space and time. Furthermore, unlike natural objects and ideal objects, they depend on subjects. In other words, without men there would be no universities, while both mountains and numbers would exist. However, and this is important to accentuate, social objects are not subjective. This means that things like promises, pacts or even debt cannot be created or, conversely, disappear at the hands of a simple mental act. ${ }^{31}$ There needs to be something more, and it is this "more" that the theory intends to capture.

Ferrarisian social ontology is founded on two underlying distinctions: the difference between types of objects (that we have just mentioned) and the difference between objects and our methods of knowledge, that Ferraris synthesizes in the distinction between ontology and epistemology (Ferraris 2012, ch. 2). To put it more simply, the former (ontology) is the doctrine of that which there is, the latter (epistemology) is the doctrine of how we know what there is. This separation does not allow for exceptions; on the one hand there is the world that remains as it is regardless of our theories, and on the other there are the theories we use to understand it.

We said that social objects are fundamental elements of social reality, irreducible, as such, to physical objects. To say it more extensively, this means that social objects are social acts that intervene between (at least) two people who possess the unique trait of being registered or inscribed somewhere-traditionally on a piece of paper, but even in a computer file, or at least in the minds of two people. Registration is one of the conditions of possibility of social objects (the other being subjects); in other words if registrations did not exist social objects would not exist either.

Therefore it is not sufficient for an act to be "said" for it to produce a social object; instead it needs to be inscribed or registered in any written format. For a promise to be a promise and have worth, my intention must be affixed on a piece of paper, or alternatively, if my interlocutor is trusting, it needs to be at least uttered out loud in such a way as to be registered in the mind of the promisee, and maybe another witness. The role of the registration is the key 
to understanding the Ferrarisian theory since it is through this registration that we believe in documents, the social objects par excellence-things like fiscal receipts, contracts, receipts of payment, fines and also less threatening social objects like works of art, or acts of matrimony. Social institutions make themselves understood evidently in the same way, and social objects like the University of Turin depend of acts produced by some subjects and inscriptions in documents. In turn they produce other acts which, aside from having worth in themselves, also have the power to cause effects (for example a diploma has the power to turn someone into a "doctor") because they are, in turn, registered in documents. 